\title{
Thomas Malvendas „De Antichristo“ (Lyon 1647) - zu einem Eckpfeiler der byzantinischen Reichseschatologie
}

\author{
Gerhard Podskalsky SJ
}

\section{Einleitung}

In meiner Dissertation „Byzantinische Reichseschatologie“ (München 1972) habe ich u.a. einen Aspekt ausgeklammert, der im Zusammenhang mit der Weltalterberechnung der Antike und des Mittelalters, aber auch mit der Figur des Endkaisers (=endzeitlichen Weltherrschers) von großer Bedeutung ist: Die Gestalt des Antichristen. ${ }^{1}$ Dieses auf biblischer Grundlage beruhende Thema wurde zum ersten $\mathrm{Mal}$ in einer umfassenden „Summa“" von dem spanischen Dominikaner Thomas Malvenda (1565/66-7.5.1628) ${ }^{2}$ behandelt; sein zuletzt 1647 in Lyon posthum erschienenes Monumentalwerk in zwei Bänden (mit 603 bzw. 246 Seiten in Großoktav) hat den Titel: „De Antichristo, in quo Antichristi praecursores, adventus, ortus, signa, regnum, bella et monarchia enumerantur; Sacrae Scripturae oracula enodantur, et Patrum auctoritates cum historiae veritate conciliantur (Band I) ; ... complectens Antichristi vitia, doctrinam, miracula, persecutiones, Iudaeorum conversionem, mundi solutionem, et ipsius Antichristi mortem." (Band II). Das mir vorliegende Exemplar stammt aus der Bibliothek St. Georgen (Signatur: Vkb=Valkenburg Ac V 154), gehörte nach einem handschriftlichen Eintrag zuvor dem Dominikanerkonvent in Osnabrück (1664), ${ }^{3}$ dann dem dortigen Collegium Paulinum (1829), ${ }^{4}$ und wurde - nach einer weiteren Bleistiftnotiz auf den inneren Einbandseiten - vermutlich 1913 in einem römischen Antiquariat für 75 Lire angeboten oder erworben. ${ }^{5}$ Das Papst Innozenz X. (1644-1655) gewidmete Werk besteht aus dreizehn

1 Vgl. ebd., S. 2, Anm. 3.

2 Zu seiner Person und seinem Gesamtwerk: vgl. J. Quétif/J. Echard (beide OP), Scriptores ordinis Praedicatorum, II, Paris 1721, S. 454-457; A. M. Walz OP, Compendium historiae ordinis Praedicatorum, Rom 1930, S. 292, 307, 332, 335, 343 f.; L. Reinhardt, Malvenda, Thomas, in: Biogr.-Bibliogr. Kirchenlex., hg. W. Bautz/T. Bautz, V, Herzberg 1993, S. 651-653; F. Dominguez, Malvenda, Thomas (=Maluenda, Tomás), in: Lex. f. Theol. u. Kirche, VI, Freiburg ${ }^{3} 1997,1255$.

3 Eintragung auf dem Titelblatt des ersten Bandes: „Ad usum F. Ambrosij Randinij ordinis Praedicatorum conventus Osnabrugiensis (1664)“.

4 Ebd.: „Nunc collegii Paulini Osn. 1829“.

5 Notiz: „Antiq. 75 Lire Ernesti Aurelij Rom 1913, Katal. 56 nr. 283“. 
Büchern (=Großkapiteln), war aber in etwas geringerem Umfang (elf Bücher) schon 1604 in Rom erschienen und 1621 in Valencia. Die mir vorliegende Ausgabe ist also die dritte und letzte.

Wer war nun dieser Thomas Malvenda? Geboren in Xátiva bei Valencia (darum der lateinische Beiname: Setabitanus), wurde Jakob Malvenda 1581 Dominikaner (Ordensname: Thomas); nach dem Studium des Lateinischen, Griechischen und Hebräischen wurde Malvenda schon 1586 Dozent für Philosophie, 1590 bis 1600 dann auch Professor für Theologie (Valencia). Er verfaßte exegetische Schriften und Kommentare zu Thomas von Aquin. Ab 1601 war er in Rom Mitarbeiter des Baronius für die „Annales“ und half auch bei der Revision der liturgischen Bücher seines Ordens. Im Auftrag der IndexKongregation beteiligte er sich ferner an der Durchsicht der „Bibliotheca SS. Patrum“ des M. de la Bigne (Paris 1589), verfaßte eine „Expurgatio“ (1607), die in späteren Auflagen mitgedruckt wurde, sowie die Annalen seines eigenen Ordens (Neapel 1627). 1608 kehrte er in seine Heimatprovinz zurück und wurde dort 1610 von der Inquisition mit der Erstellung des „Index librorum prohibitorum" beauftragt. Ab 1615 arbeitete er an einer (unvollendeten) lateinischen AT-Übersetzung (mit Kommentar), die 1650 in Lyon zum Druck kam.

Im Rückblick erscheinen all seine Projekte verbunden mit Textkritik und historischer Nachprüfung der Fakten. Was ihn zur Abfassung seines Werkes über den Antichrist bewogen hat, ist nicht bekannt. Sicher ist, daß er über 20 Jahre seines Lebens - mit Unterbrechungen wegen seiner labilen Gesundheit - daran gearbeitet hat. F. de Suárez und A. Possevino, die beiden Jesuiten, bezeugten ihm deshalb hohes Lob. Generell steht natürlich fest, daß die zweite Hälfte des 16. Jahrhunderts durch die Nachwirkung der Reformation und die Abwehrkämpfe gegen die Türken bzw. gegen den Islam die Identifizierung des Antichristen mit konkreten zeitgenössischen Gestalten sehr begünstigt hat.

\section{Inhalt des Buches}

Uns interessieren natürlich in erster Linie die Bezüge zur griechisch-byzantinischen Geschichte und Literatur. Schon Buch I, Kap. 1 (S. 2-4) enthält eine Liste aller griechischen Autoren, die in einem ihrer Werke vom Antichrist handeln; die Angaben sind ziemlich präzise (Werk, Kapitel, Edition). So sind z. B. genannt: der Philosoph Justinos und sein Dialog mit Tryphon; Eirenaios

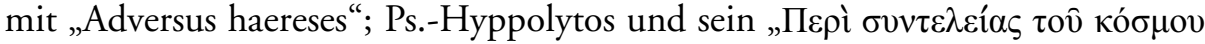

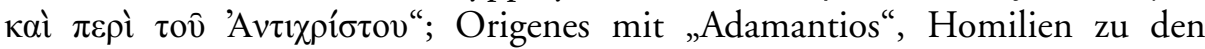
Psalmen, zu Lukas, Kommentaren zu Matthäus und Johannes, „Contra Celsum"; Athanasios von Alexandreia, Briefe an Einsiedler; (unechte) exegetische Schriften; Kyrillos von Jerusalem, Katechese 15; Ps.-Ephräm der Syrer, Rede 
über das Ende der Welt und den Antichrist (vgl. den Ps.-Hippolytos-Titel oben!); Gregorios von Nazianz, Oratio 14 und 47 sowie Teile aus den Carmina; Johannes Chrysostomos, Homilie 77 in Matthaeum, Homilie 40 in Joannem, Homilie 3 und 4 in 2 Thess., Rede über den Lohn der Heiligen; Kyrillos von Alexandreia, Genesiskommentar, Buch II; Johanneskommentar, Kap. 6; Kommetar zu Zacharias, Buch II; Theodoretos von Kyrrhos, Genesiskommentar; Kommentar zu 2 Thess., Oratio 7 und 10 in Danielem; Anastasios Sinaites, Hexaëmeron; Anastasios von Nikaia (welcher?), Quaestiones zur Hl. Schrift; Anastasios Abbas, Contra Judaeos; Leontios von Byzanz, Contra Nestorianos et Eutychianos; Johannes von Damaskos, De fide orthodoxa; Theophylaktos von Bulgarien (Achrida), Johannes-Kommentar; Kommentar zu 2 Thess.; Andreas von Kaisareia, Apokalypsen-Kommentar; Arethas von Kaisareia, ApokalypsenKommentar; Symeon Metaphrastes; Michael Psellos, „Antichristos“. Eine Psellos-Schrift mit diesem Titel ist bisher nicht bekannt geworden; nach Malvenda soll sie in einer Wiener Handschrift stehen; eine schriftliche Anfrage beim Direktor der Handschriftenabteilung der Österreichischen Nationalbibliothek (E. Gamillscheg) brachte aber kein Ergebnis (Antwortbrief vom 28.5. 2004). Das einzig dort befindliche Fragment besagten Inhalts stammt von einem Anonymus. ${ }^{6}$

Weitere von Malvenda zitierte Autoren: Olympiodoros (Diakon in Alexandreia, 6. Jh.), Kommentar zum Buch Ekklesiastes (Prediger); Oikumenios (Philosoph, 6. Jh.), Kommentar zu 2 Thess.; Euthymios Zigabenos/Zigadenos (12. Jh.), Kommentar zu Matthaeus und Johannes; Michael Glykas, Annalen (=Weltchronik); Georgios Sphrantzes, Chronikon; Germanos I. von Konstantinopel, Historia ecclesiastica; Ps.-Methodios (von Patara), Revelationes in novissimis; Methodios (Slavenapostel), Martyrologium (alte Ausgabe), Athanasios (Athonites?).

Als einziges „neues“, d.h. bisher unbekanntes Werk sticht das des Michael Psellos über den Antichrist hervor.

Es folgt wenig später ein Abschnitt über den griechischen Namen des Antichrist (S. 10-12); dann wird eine Reihe von heidnischen und jüdischen Herrschern mit der Figur des Antichrist identifiziert: Antiochos Epiphanes; Herodes, Sohn des Antipas; einige Herodianer; Simon Magus (aus der Apostelgeschichte); ein Samariter Dositheos; Bar Kochba; Apollonios von Tyana; Julian der Abtrünnige; der Häresiarch Areios; Kaiser Nero; Mohammed;

6 Vgl. H. Hunger/O. Kresten (Hgg.), Katalog der griechischen Handschriften der Österr. Nationalbibliothek, Teil 3/2: Codices theologici 101-200, Wien 1984, 415 (=Museion N.F., Vierte Reihe, Bd. I, Teil 3/2): Vindob. Theol. Gr. 193 (um 1200), ff. 224v-225r: Anonymus, De Antichristo (Fragment). - Vgl. auch: Michaelis Pselli Theologica, I, ed. P. Gautier, Leipzig 1989, 396-402 (Nr. 101): Kommentar zu Mt 24, 42-51 (ohne jede Berechnung). 
Martin Luther, so wie Luther zuvor den römischen Papst generell als Antichrist bezeichnete (S. 18-60). Das ganze zweite Buch erörtert dann die Ankunftszeit des Antichristen, ausgehend von der Weltdauer (6000 Jahre), das dritte die Herkunft des Antichristen, nämlich Babylon (= Rom, Ägypten, Bagdad?), das vierte die weltweite Verkündigung des Evangeliums als Startzeichen für Vorzeichen des Antichrist, das fünfte den Niedergang Roms als Anzeichen des Antichrist, das sechste das Reich, die Kriege und die Alleinherrschaft des Antichrist; in Band II folgen dann noch seine Lehre und seine Wunder, seine Kirchenverfolgung; ferner ist dort die Rede von den Propheten Henoch und Elia als Vorläufer des Antichrist, von der Bekehrung der Juden zu Christus, von der tausendjährigen Herrschaft Christi, von der Fesselung und Losbindung des Antichrist, von Gog und Magog (AT) und schließlich vom Tode des Antichrist. Die griechischen und lateinischen Kirchenväter sind vor allem in Buch I über die Person und Identität des Antichrist als Zeugen angeführt (im Zusammenhang mit 2 Thess. 2).

\section{Schlußbetrachtung}

Die auf biblischen Hinweisen beruhenden, aber in der konkreten Ausformulierung weit divergierenden Aussagen über den Antichrist in der Heilsgeschichte gehörten zu keiner Zeit zum Credo der christlichen Kirchen; aber trotz der in den Evangelien überdeutlich bezeugten Unberechenbarkeit des Weltendes wucherten die Spekulationen über die Herkunft, Zeit und Wirksamkeit des Antichristen unbeirrt durch alle Jahrhunderte fort. Im Jahre 1647, ein Jahr vor Beendigung des Dreißigjährigen Krieges, waren Gegenreformation und Türkenkreuzzüge, die konkreten Anlässe für die Abschreckung durch das Erscheinen des Antichrist, schon im Abklingen begriffen. Thomas Malvenda hatte seine Monographie wohl auch verfaßt als Exempel seiner umfassenden philologischen und historischen Kenntnisse und Interessen. 


\section{R.P.F.T H O M \\ MALVENDA \\ SET A B I T A N I \\ ORD. PRADICATORVM \\ Sacræ Theologiæ Magiftri, \\ $\mathcal{D} E$

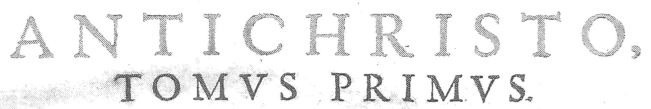

IN OUOANTICHRISTIPRACYRSORES,ADVENYYS. Ortus, figna, regnum, bella \& morarchia enumerantur; Sacre Scriptura oracula enodantur, \& Patrum auctoritates cum Hiftoria Deritate conciliantur.

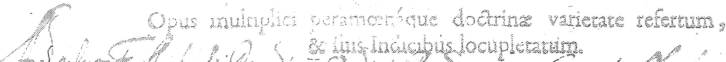

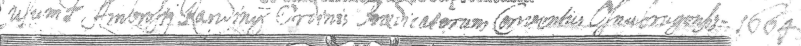

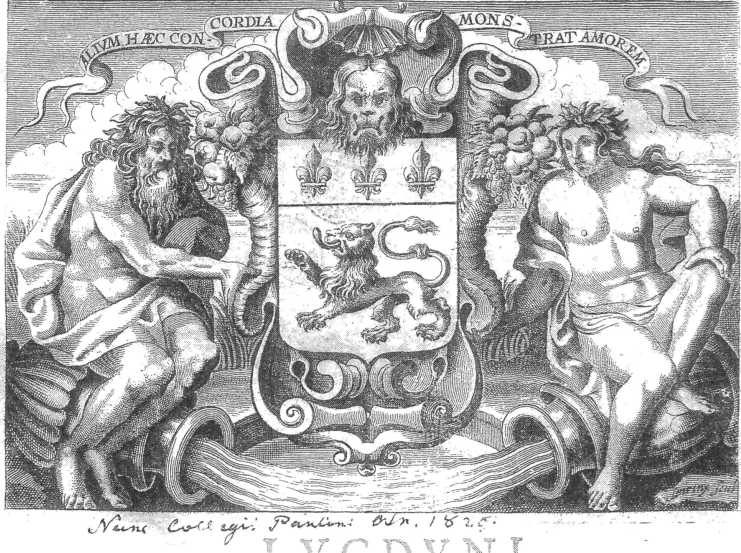

I VGDVNIs

Sumptibus Societatis Bibliopolarum.

SN. DC. XLVTH

Cum Approbatione, \& permiffu Superiorum.

$14+\pi$ 
